\title{
Randomized, controlled crossover study of IVIg for demyelinating polyneuropathy and diabetes
}

Ari Breiner, MD, MSc, FRCPC, Carolina Barnett Tapia, MD, PhD, Leif Erik Lovblom, MSc, Bruce A. Perkins, MD, MPH, FRCPC, Hans D. Katzberg, MD, MSc, FRCPC, and Vera Bril, MD, FRCPC

Neurol Neuroimmunol Neuroinflamm 2019;6:e586. doi:10.1212/NXI.0000000000000586

\section{Abstract}

\section{Objective}

To determine whether IV immunoglobulin (IVIg) is more effective than placebo at reducing disability in patients with diabetes and demyelinating polyneuropathy features.

\section{Methods}

This is a double-blinded, single-center, randomized, controlled crossover trial of IVIg treatment vs placebo. The primary outcome measure was the mean change in Overall Neuropathy Limitation Scale (ONLS) scores during the IVIg phasecompared with the placebo phase. Secondary outcomes include changes in the Rasch-built Overall Disability Scale, Medical Research Council sum scores, grip strength, electrophysiologic measurements, quality of life, and adverse effects.

\section{Results}

Twenty-five subjects were recruited between March 2015 and April 2017. The mean change in ONLS scores was -0.2 points during the IVIg phase and 0.0 points during the placebo phase $(p$ $=0.23$ ). Secondary outcomes did not show significant differences between IVIg and placebo.

\section{Conclusions}

IVIg did not reduce disability, improve strength, or quality of life in patients with demyelinating polyneuropathy features and diabetes after 3 months of treatment in comparison with placebo. Therefore, careful consideration of the primary diagnosis is required before immunomodulatory therapy.

\section{Classification of evidence}

This study provides Class I evidence that for patients with diabetes and demyelinating polyneuropathy features, IVIg did not significantly reduce disability.

\author{
Correspondence \\ Dr. Breiner \\ abreiner@toh.ca
}

MORE ONLINE

$\rightarrow$ Class of Evidence

Criteria for rating therapeutic and diagnostic studies

NPub.org/coe 


\section{Glossary}

$\mathrm{AE}=$ adverse event; $\mathbf{A N C O V A}=$ analysis of covariance; $\mathbf{C I D P}=$ chronic inflammatory demyelinating polyneuropathy; $\mathbf{D M}=$ diabetes mellitus; DSP = diabetic sensorimotor polyneuropathy; EFNS = European Federation of Neurological Societies; IQR = interquartile range; IVIg = IV immunoglobulin; LLN = lower limit of normal; MRC = Medical Research Council; NCS = nerve conduction study; ONLS = Overall Neuropathy Limitation Scale; R-ODS = Rasch-based Overall Disability Scale; SF = Short Form 36-item; ULN = upper limit of normal.

There is a broad spectrum of polyneuropathy in patients with diabetes-including distal symmetrical sensorimotor polyneuropathy (DSP), proximal neuropathies/plexopathies, and demyelinating peripheral neuropathies. The recognition of chronic inflammatory demyelinating polyneuropathy (CIDP) in patients with diabetes is important, as CIDP is a treatable, demyelinating peripheral neuropathy with a suspected autoimmune etiology. ${ }^{1}$ The hallmark clinical findings are symmetrical proximal and distal limb weakness, sensory loss, and absent deep tendon reflexes. ${ }^{1-3}$

IV immunoglobulin (IVIg) is a safe and effective treatment for CIDP both in short- and medium-term time horizons. ${ }^{4-10}$ However, in patients with diabetes mellitus (DM), the optimal treatment regimen for CIDP remains unknown, as patients with diabetes have been excluded from randomized controlled clinical trials, ${ }^{5-8,11}$ due to concerns that their neuropathy may be secondary to diabetes, rather than an autoimmune or inflammatory process. In addition to the absence of prospective data regarding treatment response, there are significant challenges to diagnosing CIDP in patients with diabetes. These challenges stem from overlap between electrophysiologic changes due to DSP and those due to CIDP. Although diabetic polyneuropathy is considered a primarily axonal process, many authors have reported electrophysiologic evidence of conduction velocity slowing and other demyelinating findings, ${ }^{12,13}$ out of proportion to what would be expected in a purely axonal polyneuropathy. ${ }^{14,15}$ These nerve conduction study (NCS) changes have been linked to localized foci of demyelination and remyelination, ${ }^{16}$ and some authors have reported inflammatory features (i.e., perivascular inflammatory cell infiltrates) in nerve biopsies of patients with diabetes. ${ }^{17}$ The result is demyelinating-range NCS changes in patients with diabetes, making a distinction between those with CIDP + DSP and those with isolated DSP increasingly difficult. The coexistence of diabetes and CIDP in the same patient is a relatively common occurrence $(4 \%-65 \%$ of patients with CIDP have diabetes ${ }^{18-23}$ ) and is expected to only increase with rising diabetes prevalence worldwide. In the medical literature, there is conflicting opinion whether CIDP is more prevalent in patients with diabetes than patients without diabetes, ${ }^{23-26}$ but no convincing epidemiologic data to support an association. However, the overall uncertainty underscores the need for further research to distinguish between DSP and CIDP. ${ }^{27}$

Because of the lack of prospective studies, there is a knowledge gap with regard to the appropriate method of diagnosing and treating demyelinating polyneuropathies in patients with coexistent diabetes. Previous work from our group has shown that NCSs may be confounded by abnormalities due to diabetic polyneuropathy. ${ }^{13,28,29}$ Moreover, the effect of IVIg treatment is uncertain in this population, as it has never been studied prospectively. Therefore, we performed a crossover study to examine IVIg treatment responses in patients with diabetes and demyelinating NCS changes, with the goal of determining whether IVIg could reduce disability in this population.

\section{Methods}

\section{Study design and participants}

We performed a randomized, double-blind, placebo-controlled crossover study to test superiority of IVIg vs placebo $(0.9 \%$ $\mathrm{NaCl}$ in water) in patients with diabetes and demyelinating polyneuropathy features. Study recruitment occurred at a single center (Toronto General and Western Hospital sites of the University Health Network) in Toronto, Canada.

Patients were eligible to participate if they were aged $\geq 18$ years and had both DM (as per the American Diabetes Association Criteria ${ }^{30}$ ) and clinical evidence of polyneuropathy. In addition, at least 2 separate motor nerves (median, ulnar, tibial, or peroneal) had to meet the following electrodiagnostic criteria for demyelination: (1) conduction velocity $<90 \%$ of the lower limit of normal, distal latency $>110 \%$ upper limit of normal (ULN), or minimal F-wave latency $>110 \%$ ULN and (2) electrodiagnostic changes not exclusively due to median neuropathy at the wrist, ulnar neuropathy at the elbow, or peroneal neuropathy at the fibular head. Finally, to be considered eligible, there had to be clinical suspicion of possible demyelinating polyneuropathy (CIDP) on the part of the treating neuromuscular specialist (e.g., proximal limb weakness or significant ataxia, out of proportion to the degree of axonal loss).

Potential subjects were excluded if they had a history of hereditary polyneuropathy (Charcot-Marie-Tooth disease), other potential confounding causes of polyneuropathy (including heavy alcohol consumption, uremia, and gammopathyassociated polyneuropathy), contraindication to IVIg treatment, or a serious/unstable medical condition precluding its use. The full list of inclusion and exclusion criteria is found in the appendix (table e-1, links.lww.com/NXI/A126). 


\section{Standard protocol approvals, registrations, and patient consents}

Ethics approval was obtained through the research ethics board of the University Health Network Hospital (University of Toronto). The study was registered on clinicaltrials.gov (Registration \#NCT02372149). Written informed consent was obtained from all study participants. As this is a clinical trial, there are no photographs, videos, or other recognizable information being published.

\section{Randomization and masking}

Allocation was performed in a 1:1 ratio for the initial infusion type (IVIg or placebo), with block randomization in groups of 5 . Sequence generation was performed by the unblinded study co-coordinator, who was also responsible for documenting and maintaining the master list of allocation assignments.

IVIg was obtained through the blood bank and prepared in the pharmacy before administration. It was transferred to clear polypropylene bags, which were draped with bronze translucent covers. Placebo $(0.9 \% \mathrm{NaCl})$ infusions consisted of the identical volume of fluid in an identical polypropylene bag covered by an identical bronze translucent shield. All bags were labeled only with the patient's unique study ID number. The evaluating physicians, study infusion nurse, and patients did not have access to the list of allocation assignments. Only the pharmacists and one study coordinator were not blinded; these unblinded individuals were not allowed to contact the investigators or patients.

\section{Procedures}

Study infusions and procedures have been summarized in figure 1. Gamunex IVIg (Grifols, Inc) was administered as an initial loading dose of $2.0 \mathrm{~g} / \mathrm{kg}$ divided in 2 days, with a maximum daily dose of $80 \mathrm{~g}$ (month 0 ). This was followed by a monthly maintenance dose of $1.0 \mathrm{~g} / \mathrm{kg}$ at months 1,2 , and 3 . This dosing regimen for IVIg was derived from previous CIDP trials. ${ }^{6,7,9}$ IVIg infusions were started at a rate of $0.01 \mathrm{~mL} / \mathrm{kg} / \mathrm{min}$ and increased as per patient tolerance to a maximum of $0.08 \mathrm{~mL} / \mathrm{kg} /$ $\mathrm{min}$. Subjects who began treatment with placebo followed the same infusion schedule. Following the 3rd maintenance infusion, there was a 3-month washout period. Subjects randomized to IVIg in the second treatment phase received their $2.0 \mathrm{~g} / \mathrm{kg}$ loading dose at month 6 , followed by $1.0 \mathrm{~g} / \mathrm{kg}$ maintenance dosing at months 7,8 , and 9 . The length of the washout period was selected based on the half-life of IVIg and the expected duration of benefit after monthly administration.

The primary research question was whether IVIg could reduce disability in patients with diabetes and demyelinating polyneuropathy features in comparison with placebo (Class I level of evidence). We assessed the efficacy of IVIg using the Overall Neuropathy Limitation Scale (ONLS-primary outcome measure), the Rasch-based Overall Disability Scale (RODS), the Medical Research Council (MRC) sum score, Grip Strength, NCSs, and a generic quality of life score Short Form 36-item (SF-36).
The ONLS scale is a disability questionnaire with a score that ranges from 0 (no disability) to 12 (severe disability). It has been validated in 100 patients with inflammatory polyneuropathy and has strong correlation $(\mathrm{r}=0.97)$ with the Overall Disability Sum Score. ${ }^{31}$ Therefore, it is the reference standard for inflammatory polyneuropathy trials. ${ }^{7,9,10}$ The R-ODS score is a disability questionnaire with a score that ranges from 0 (severe disability) to 48 (no disability). Compared with the ONLS score, it may provide a better overall measure of disability, a wider range of item difficulties, and a rational method for item weighting. ${ }^{32}$ The MRC sum score ranges from 0 (total paralysis) to 80 (normal strength) and is the sum of the MRC score of 8 muscles (4 upper and 4 lower limb), each graded from 0 to 5. Grip strength is measured using the Martin Vigorimeter in kilopascals. Three trials were measured in each hand, and the average recorded. This is a relevant outcome because it relates to hand dexterity and strength, which are important for daily tasks. The SF-36 is a self-administered questionnaire that measures physical functioning, role limitations due to physical problems, social functioning, bodily pain, mental health, role limitations due to emotional problems, vitality, and general health. The assessments were performed at screening (within 3 weeks of the first infusion) and at the month 3, 6, and 9 study visits. The ONLS and R-ODS scores were also repeated at the initial infusion visit (month 0 ) to ensure that there had been no decline or spontaneous improvement since the screening visit. A telephone follow-up occurred at months 4 and 10, which consisted of the ONLS and R-ODS scores and adverse event (AE) monitoring. For the purpose of data analysis, the month 3 and 9 ONLS scores were used.

AE monitoring occurred during each clinical visit and each IVIg/placebo infusion. Patients with serious or intolerable AEs had all treatments stopped and were withdrawn from the study after discussion with the principal investigator. Patients with ongoing or catastrophic deterioration ( $\geq 3$-point increase in the ONLS score with $\geq 2$-point increase in the lower extremities) had their case assessed by the principal investigator to determine whether they should be unblinded and treated with either the active treatment or plasmapheresis.

\section{Electrodiagnostic studies}

NCSs were performed using Sierra Wave equipment (Cadwell Laboratories Inc, Kennewick, WA), using surface stimulating and recording electrodes, according to standardized protocols. ${ }^{33,34}$ Skin temperature was maintained at $\geq 32.0^{\circ} \mathrm{C}$ in the hands and $\geq 31.0^{\circ} \mathrm{C}$ in the feet. We studied the responses of the median, ulnar, tibial, and peroneal motor nerves on the more affected side and the sensory responses of the median, ulnar, and sural nerves on the more affected side.

\section{Outcomes}

The primary efficacy outcome was comparison of the mean ONLS change score in the experimental and placebo phases. Secondary outcomes were comparison of mean change 


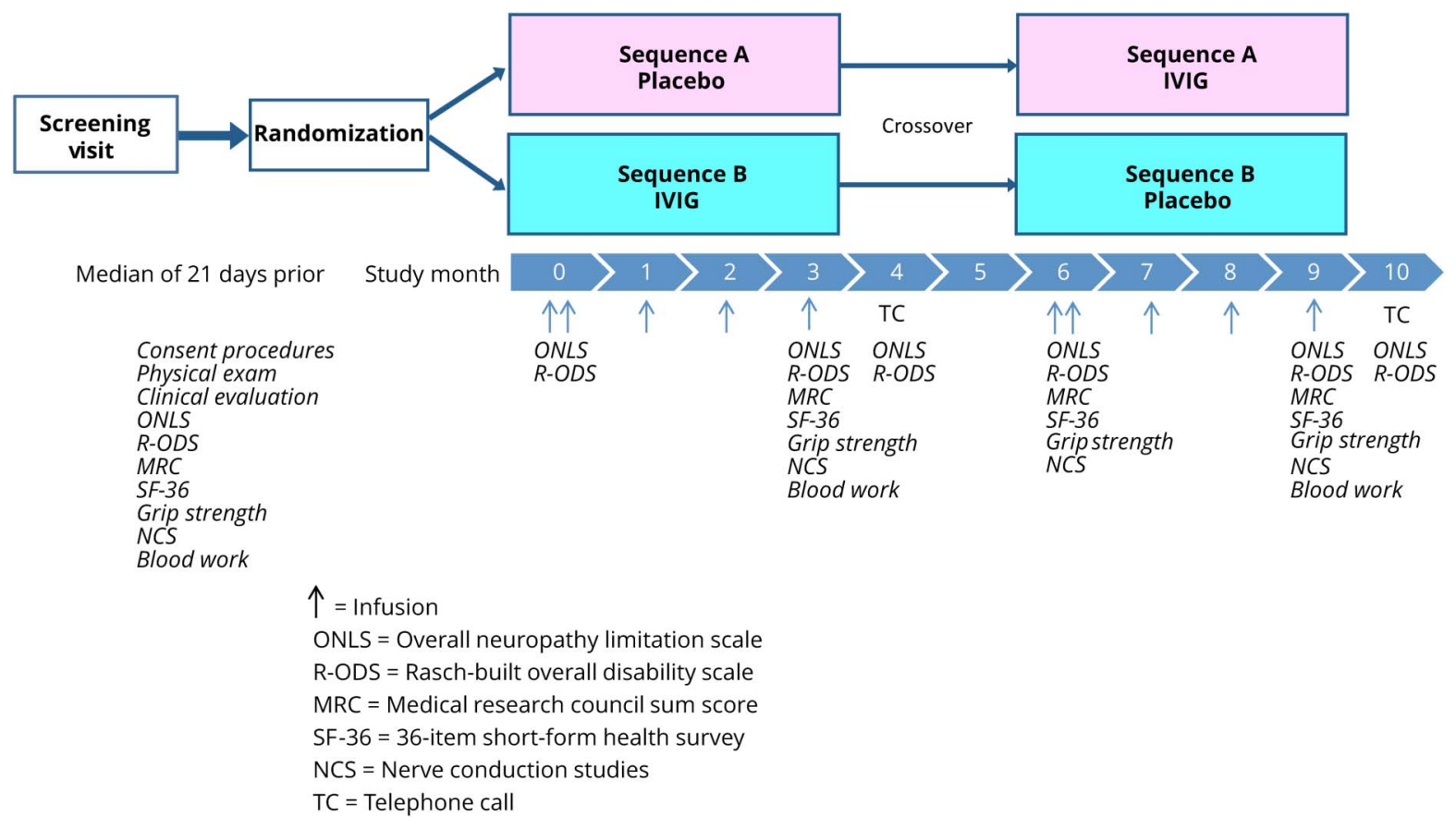

IVIG = IV immunoglobulin.

scores, during experimental and placebo phases, for the following end points: (1) R-ODS score, (2) MRC sum score, (3) grip strength, (4) NCS parameters (distal latency, conduction velocity, and compound motor action potential [CMAP] amplitude), and (5) SF-36 (total score). We also compared $\mathrm{AE}$ rates during the experimental and placebo phases.

\section{Statistical analysis}

Statistical analyses were performed using SAS version 9.4 for Windows (SAS Institute, Cary, NC). Summary statistics are presented as mean $\pm \mathrm{SD}$, median and interquartile range (IQR), or as frequency (\%). The changes in primary and secondary outcomes were compared between IVIg and placebo phases using 2 methods: (1) an unadjusted analysis using the paired Student $t$ test and (2) an adjusted analysis using repeated-measures analysis of covariance (ANCOVA) with the change score as the dependent variable, and study phase (IVIg or placebo), sequence, and baseline value as the independent variables. The adjusted means and 95\% confidence intervals of the change scores are presented. We made all comparisons on the intention-to-treat data set, and we considered an $\alpha$-level of 0.05 (2-sided) for all tests of statistical significance.

We assessed the carryover effects using the Student $t$ test. To account for carryover effects, an exploratory analysis of sequence effect compared participants randomized to placebo first vs those randomized to IVIg first. This was done using (1) an unadjusted Student $t$ test analysis and (2) an adjusted (ANCOVA) analysis with the change score as the dependent variable and sequence and baseline value as the independent variables. Comparison of responders was made using the McNemar test. To compare the rates of AEs, we used the $\mathrm{McNemar}$ test and conditional maximum likelihood estimates of the rate ratios.

We calculated the sample size using data from a large randomized trial of IVIg in patients with CIDP. ${ }^{7}$ In that study, the mean baseline ONLS score was 4.1 with a within-group $\mathrm{SD}$ of 1.4. However, calculation of the sample size for a crossover study ${ }^{35}$ requires within-patient $\mathrm{SD}$, which is not available for patients with inflammatory neuropathy. ${ }^{36}$ Therefore, rather than using within-group SD (1.4), which would provide a very conservative estimate for the sample size, we estimated a more realistic within-patient SD of 1.0 ONLS point-also reflecting the change in the ONLS score reported to be clinically significant, on comparison with quality of life measures. ${ }^{37}$ Based on these data, the calculated sample size was 18 patients, with $80 \%$ power and $\alpha=0.05$. Therefore, enrollment was planned for 25 patients to account for potential dropouts.

\section{Data availability}

Individual participant data that underlie the results reported in this article (including text, tables, figures, and appendices) will be available after deidentification. It will be available for 5 years after publication, to researchers who provide a methodologically sound proposal, for the purposes of conducting a prespecified analysis. Data will be accessed by sending an email to the corresponding author. 


\section{Results}

Between March 2015 and April 2017, 74 patients were approached for participation. Of these, 33 underwent screening, and 25 met the criteria for enrollment. Fourteen patients were assigned to IVIg and 11 to placebo for the first intervention. In the placebo-first group, 2 patients dropped out after the month 0 visit. In the IVIg-first group, 1 patient dropped out after the month 3 visit and 1 patient after the month 6 visit. Reasons for dropout included adverse effects of aching and swelling (1), limited reimbursement for study visits (1), withdrew consent (1), and expired secondary to pancreatitis (1). The CONSORT diagram is displayed in figure 2.

Table 1 displays baseline demographic information for the 25 enrolled subjects. The mean age was $57.5 \pm 9.2$ years, and $68 \%$ were male. In those patients who underwent lumbar puncture $(\mathrm{n}=12)$, the mean CSF total protein was $0.97 \pm 0.55 \mathrm{~g} / \mathrm{L}$. CSF total protein was above $0.45 \mathrm{~g} / \mathrm{L}$ in $11 / 12$ patients and was above $0.60 \mathrm{~g} / \mathrm{L}$ in $10 / 12$ patients. At baseline, $84 \%$ of patients had symptoms of weakness or neuropathic pain in the lower extremities, $60 \%$ had upper limb neuropathic pain, $68 \%$ had upper limb weakness, and $79 \%$ of subjects had imbalance. Proximal weakness of the upper or lower limbs was present in
$68 \%$ of patients. This was defined as muscle power of $4 / 5$ or less on the MRC sum scoring in muscle groups proximal to the elbow (i.e., deltoid or biceps) or the knee (quadriceps or iliopsoas). At baseline, the mean ONLS score was $4.2 \pm 1.7$, the mean R-ODS score was $30.8 \pm 7.8$, and the mean grip strength was $58.4 \pm 17.4 \mathrm{kPA}$ (table 1).

Table 2 demonstrates the mean change scores for each of primary and secondary end points. As shown, the $p$ values for primary and secondary outcomes are not significantly different. The mean change score for ONLS (primary outcome) was -0.2 points during the IVIg phase and 0.0 points during the placebo phase (unadjusted $p=0.23$ ). Adjusted $p$ values were computed using ANCOVA analysis-with adjustment for sequence order and baseline value-however, again differences did not reach statistical significance.

AE rates did not differ significantly between placebo and IVIg. In total, there were $26 \mathrm{AEs}$ during the placebo phase and 22 in the IVIg phase $(p=0.45)$. The proportion of patients with $\geq 1 \mathrm{AE}$ was $9 / 24(38 \%)$ in the placebo phase and $9 / 23(39 \%)$ in the IVIg phase $(p=0.32)$. Most AEs were mild or moderate in severity—including fatigue/dizziness/lightheadedness (12.8\%), swelling (12.8\%), body pain (10.6\%), nausea/vomiting/gastric

Figure 2 Consort diagram

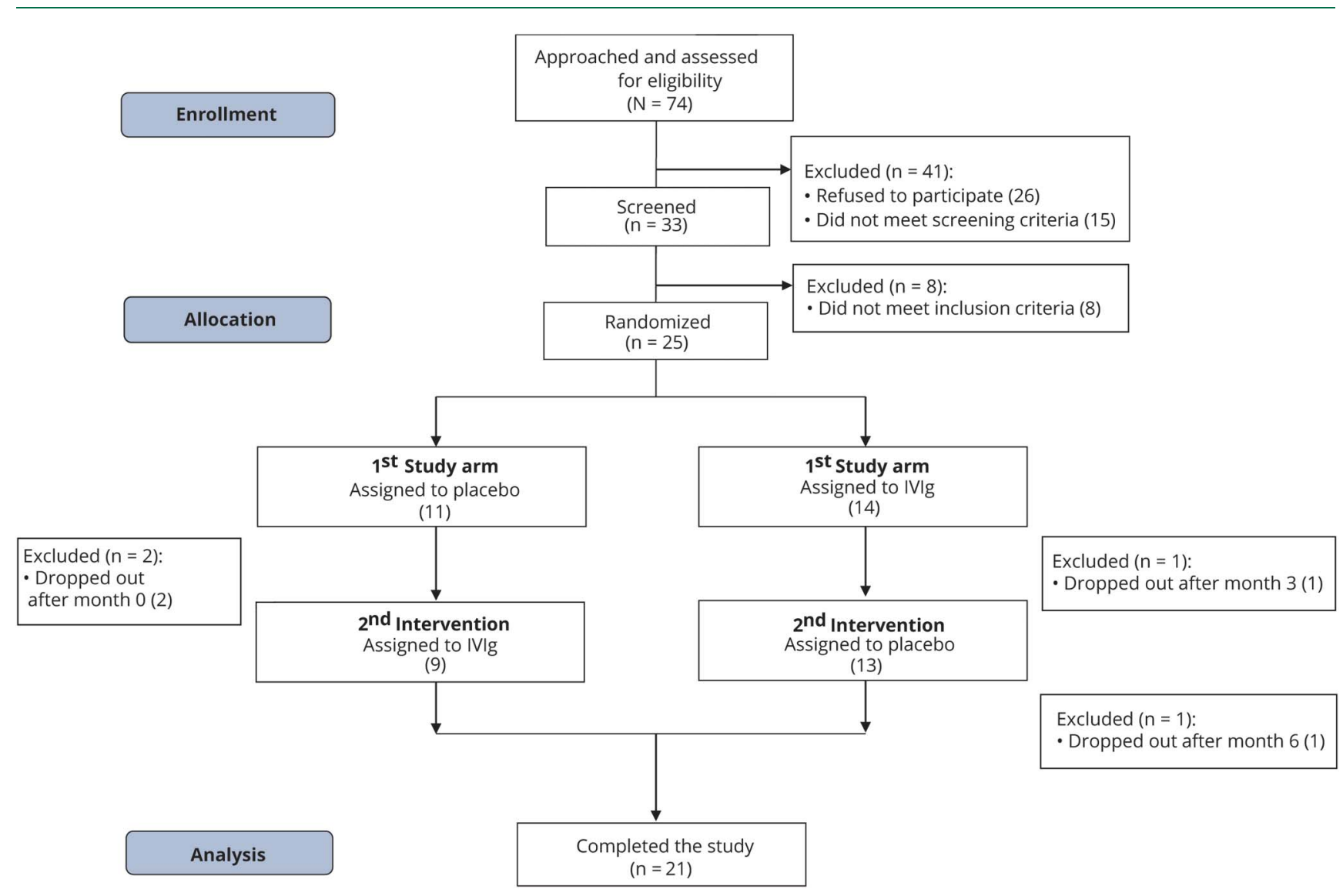

$\mathrm{IVIg}=\mathrm{IV}$ immunoglobulin. 
Table 1 General clinical characteristics of the 25 patients who were randomized

\begin{tabular}{ll}
\hline Characteristic & $\begin{array}{l}\text { Mean } \pm \text { SD, median (IQR), or } \\
\text { frequency (\%) }\end{array}$ \\
\hline Age (y) & $57.5 \pm 9.2$ \\
\hline Height (m) & $1.73 \pm 0.11$ \\
\hline Weight (kg) & $91.5 \pm 23.9$ \\
\hline BMI (kg/m ${ }^{2}$ ) & $30.3 \pm 6.2$ \\
\hline Female sex/male sex & $8(32 \%) / 17(68 \%)$ \\
\hline Smoking history & $2(8 \%)$ \\
\hline Yes & $8(33 \%)$ \\
\hline Quit & $14(58 \%)$ \\
\hline Never & $11[4,25]$ \\
\hline Diabetes duration (y) & $5.5[2,10]$ \\
\hline Polyneuropathy duration (y) & $0.97 \pm 0.55$ \\
\hline CSF total protein (n = 12) (g/L) & $2(8 \%)$ \\
\hline
\end{tabular}

Clinical symptoms

\begin{tabular}{lc}
\hline Numbness, lower limbs & $19(76 \%)$ \\
\hline Numbness, upper limbs & $15(60 \%)$ \\
\hline Paresthesia, lower limbs & $16(64 \%)$ \\
\hline Paresthesia, upper limbs & $12(48 \%)$ \\
\hline Weakness, lower limbs & $21(84 \%)$ \\
\hline $\begin{array}{l}\text { Weakness, upper limbs } \\
\text { Proximal weakness }\end{array}$ & $24(95 \%)$ \\
\hline $\begin{array}{l}\text { Neuropathic pain, lower } \\
\text { limbs }\end{array}$ & $21(84 \%)$ \\
\hline $\begin{array}{l}\text { Neuropathic pain, upper } \\
\text { limbs }\end{array}$ & $15(60 \%)$ \\
\hline $\begin{array}{l}\text { Imbalance } \\
\text { Falls }\end{array}$ & $11(79 \%)$ \\
\hline
\end{tabular}

Baseline outcome measures

\begin{tabular}{ll}
\hline ONLS & $4.2 \pm 1.7$ \\
\hline R-ODS & $30.8 \pm 7.8$ \\
\hline Grip strength & $58.4 \pm 17.4$ \\
\hline SF-36 & $36.8 \pm 19.7$ \\
\hline MRC grade & $71.5 \pm 6.4$
\end{tabular}

Abbreviations: $\mathrm{BMI}=$ body mass index; $\mathrm{CV}=$ conduction velocity; IQR = interquartile range; IVIg = IV immunoglobulin; $\mathrm{MRC}=$ Medical Research Council; ONLS = Overall Neuropathy Limitation Score; R-ODS = Rasch-based Overall Disability Score; SF-36 = 36-Item Short Form Health Survey. pain (8.5\%), headache (6.4\%), rash/itching (6.4\%), dyspnea/ chest tightness (6.4\%), and neck stiffness/joint pain (6.4\%). Only 1 serious AE occurred during the trial, at the month 8 mark. A patient receiving IVIg developed pancreatitis and subsequently expired; this event was not considered to be related to study treatment, but rather to a previous history of cholelithiasis.

Post hoc exploratory analyses were performed to determine whether the lack of treatment effect could be attributed to (1) order of administration, (2) timing of end point measurement, or (3) intention-to-treat-rather than per-protocol—analysis. The findings consistently showed no significant differences between groups, with one exception (appendix and table e-2, links.lww.com/NXI/A126). When patients were stratified based on treatment with placebo first or IVIg first, those randomized to IVIg first showed a reduction in the mean ONLS score $(-1.0$ vs +0.3 points, $p=0.018)$, even after adjustment for sequence order and baseline value (adjusted $p=0.020$ ). In this exploratory subgroup analysis, the secondary outcomes did not show significant change, although there was a positive trend for the R-ODS and SF-36. There was also evidence of a carryover effect on the ONLS score $(p=0.017)$, whereas no carryover effect was observed for R-ODS, grip strength, SF-36, or MRC score. This carryover effect was most probably driven by the "IVIg-first" effect described above.

Given the possible clinical benefit in the IVIg-first subgroup, we reanalyzed the baseline data after stratifying by order of administration. The only significant difference was in the duration of neuropathy (appendix and table e-3, links.lww.com/NXI/ A126), which had a median (IQR) of $10(6-10)$ years in the placebo-first group and 3 (2-6) years in the IVIg-first group ( $p=$ 0.033 ). Additional exploratory analyses were also performed in the subgroup of patients who met the definite European Federation of Neurological Societies (EFNS) electrodiagnostic criteria for patients with CIDP $(18 / 25) .{ }^{38}$ Within this subgroup, there was no significant benefit to IVIg administration (change in the ONLS score of -0.2 in the IVIg phase and +0.1 in the placebo phase, $p=0.19$, and change in the R-ODS score of +1.1 in the IVIg phase and +0.2 in the placebo phase, $p=0.29$ ). In the subgroup who did not meet the EFNS electrodiagnostic criteria, there was 1 patient who improved during the IVIg phase (from ONLS 4 to 2) and 1 patient who improved with placebo. Finally, an exploratory responder analysis showed improvement of $\geq 1$ ONLS point in 9/23 (39\%) of IVIg phases and 5/21 (24\%) of placebo phases, although the result did not reach statistical significance $(p=0.32)$. Improvement of $\geq 2$ ONLS points was observed in only 3 patients_all during the IVIg phase.

\section{Discussion}

The diagnosis and treatment of demyelinating polyneuropathy in the setting of diabetes is a unique challenge. First, patients with diabetes have been excluded from CIDP trials because of concerns about confounding effects of the 2 
Table 2 Outcomes according to study arm

\begin{tabular}{|c|c|c|c|c|c|c|}
\hline \multirow[b]{2}{*}{ Outcome } & \multicolumn{2}{|c|}{ Placebo, $n=24$} & \multicolumn{2}{|l|}{ IVIg, $n=23$} & \multicolumn{2}{|c|}{$p$ Value for drug effect ${ }^{b}$} \\
\hline & Baseline & $\Delta(95 \% \mathrm{Cl})^{\mathrm{a}}$ & Baseline & $\Delta(95 \% \mathrm{Cl})^{\mathrm{a}}$ & Unadjusted $p$ value & Adjusted $p$ value \\
\hline \multicolumn{7}{|l|}{ Primary } \\
\hline ONLS & $4.0 \pm 1.7$ & $0.0(-0.4$ to 0.4$)$ & $4.3 \pm 1.6$ & $-0.2(-0.6$ to 0.1$)$ & 0.23 & 0.38 \\
\hline \multicolumn{7}{|l|}{ Secondary } \\
\hline R-ODS & $30.2 \pm 8.9$ & $0.0(-3.1$ to 3.1$)$ & $30.3 \pm 7.3$ & $+1.0(-2.0-4.0)$ & 0.27 & 0.37 \\
\hline Grip strength & $56.5 \pm 16.5$ & $-0.1(-4.8$ to 4.5$)$ & $58.0 \pm 16.3$ & $-4.0(-8.4$ to 0.4$)$ & 0.16 & 0.22 \\
\hline SF-36 & $40.9 \pm 22.1$ & $+3.4(-2.0-8.8)$ & $38.4 \pm 20.3$ & $+2.1(-3.1-7.3)$ & 0.88 & 0.73 \\
\hline MRC grade & $71.0 \pm 6.5$ & $-0.1(-1.6$ to 1.3$)$ & $71.4 \pm 6.8$ & $+0.5(-0.9$ to 1.9$)$ & 0.70 & 0.54 \\
\hline \multicolumn{7}{|c|}{ Motor nerve conduction } \\
\hline \multicolumn{7}{|l|}{ Median nerve } \\
\hline Latency, wrist & $5.1 \pm 1.8$ & $0.0(-0.3$ to 0.2$)$ & $5.2 \pm 2.3$ & $0.0(-0.2$ to 0.3$)$ & 0.95 & 0.73 \\
\hline Amplitude, wrist & $6.4 \pm 3.4$ & $0.5(0.0$ to 1.0$)$ & $6.7 \pm 3.8$ & $0.3(-0.2$ to 0.8$)$ & 0.51 & 0.38 \\
\hline CV, forearm & $41.2 \pm 5.9$ & $+0.6(-0.2$ to 1.4$)$ & $41.4 \pm 5.6$ & $0.0(-0.8$ to 0.8$)$ & 0.21 & 0.21 \\
\hline \multicolumn{7}{|l|}{ Ulnar nerve } \\
\hline Latency, wrist & $3.4 \pm 1.1$ & +0.4 (0.0 to 0.8$)$ & $3.7 \pm 1.4$ & $0.0(-0.4$ to 0.4$)$ & 0.16 & 0.14 \\
\hline Amplitude, wrist & $5.0 \pm 3.1$ & $+0.2(-0.2$ to 0.6$)$ & $5.1 \pm 3.6$ & $+0.2(-0.2$ to 0.6$)$ & 0.58 & 0.92 \\
\hline CV, below elbow & $40.9 \pm 8.0$ & $-1.1(-4.4$ to 2.3$)$ & $41 \pm 7.8$ & $-1.0(-4.4$ to 2.4$)$ & 0.92 & 0.94 \\
\hline \multicolumn{7}{|l|}{ Peroneal nerve } \\
\hline Latency, ankle & $10.5 \pm 6.0$ & $+0.7(-2.0-3.4)$ & $11.0 \pm 7.0$ & $+0.6(-2.1-3.3)$ & 0.55 & 0.79 \\
\hline Amplitude, ankle & $0.9 \pm 1.5$ & $0.0(-0.2$ to 0.1$)$ & $0.9 \pm 1.5$ & $+0.1(-0.1$ to 0.2$)$ & 0.18 & 0.24 \\
\hline CV, lower leg & $29.0 \pm 5.3$ & $-0.5(-1.7$ to 0.6$)$ & $28.3 \pm 4.8$ & $+0.5(-0.6$ to 1.7$)$ & 0.18 & 0.14 \\
\hline \multicolumn{7}{|l|}{ Tibial nerve } \\
\hline Latency, ankle & $9.4 \pm 5.1$ & $-0.1(-0.5$ to 0.2$)$ & $9.9 \pm 5.1$ & $-0.5(-0.8$ to 0.1$)$ & 0.093 & 0.14 \\
\hline Amplitude, ankle & $1.3 \pm 2.2$ & $-0.2(-0.3$ to 0.0$)$ & $1.2 \pm 2.1$ & $-0.1(-0.2$ to 0.1$)$ & 0.12 & 0.30 \\
\hline CV, lower leg & $29.9 \pm 4.5$ & $+0.5(-0.2$ to 1.2$)$ & $29.1 \pm 4.2$ & $+0.1(-0.6$ to 0.8$)$ & 0.48 & 0.36 \\
\hline \multicolumn{7}{|c|}{$\begin{array}{l}\text { Abbreviations: CV = conduction velocity; IVIg = IV immunoglobulin; MRC = Medical Research Council; ONLS = Overall Neuropathy Limita } \\
\text { Rasch-based Overall Disability Score; SF-36 = 36-Item Short Form Health Survey. } \\
\text { Baseline values displayed as mean } \pm \text { SD. } \\
\text { Nerve conduction latencies displayed in } \mathrm{ms} \text {, amplitudes in } \mathrm{mV} \text {, and conduction velocities in } \mathrm{m} / \mathrm{s} \text {. } \\
\text { a Intention-to-treat analysis. } \\
\text { b Unadjusted } p \text { value from the paired Student } t \text { test; adjusted } p \text { value from ANCOVA adjusted for sequence order and baseline value. }\end{array}$} \\
\hline
\end{tabular}

neuropathies. Second, the diagnosis of CIDP in a patient with diabetes may prove especially challenging, as diabetic neuropathy alone may produce signs of demyelination on nerve conduction testing. Third, there is often considerable overlap of clinical features and CSF profile. Fourth, there is no specific biomarker for either disease.

In this study, we enrolled 25 patients with diabetes and features of demyelination on NCSs, aiming to determine whether IVIg is an effective treatment to reduce disability, increase muscle strength, and improve quality of life. We found no significant benefit to treating with IVIg. As noted in table 2, there was no significant difference in mean change scores for the primary or secondary outcome measures after 3 months of treatment, even with adjusted $p$ values (using an ANCOVA model) to account for baseline values.

The primary findings in this study suggest that patients with diabetes and demyelinating polyneuropathy features should not be empirically treated with IVIg, unless the clinical picture is convincing for CIDP. Some suggestions might include restricting to those cases with (1) significant proximal weakness, (2) definite conduction block, (3) shorter neuropathy duration, or (4) those patients meeting more conservative CIDP criteria (American 
Academy of Neurology or Inflammatory Neuropathy Cause and Treatment criteria). Similar suggestions for distinguishing CIDP from proximal forms of diabetic polyneuropathy have been proposed by other authors. ${ }^{19,39}$ The results of this study do not exclude the possibility of superimposed CIDP in a patient with diabetes; nor should they be used to deny IVIg treatment to patients with CIDP and diabetes. Rather, the findings in this negative study highlight the importance of a cautious approach to diagnosing CIDP, particularly in the diabetic population.

Post hoc exploratory analyses of our data resulted in several interesting findings and raised some further questions. First, a responder analysis showed improvement of $\geq 1$ ONLS point in 9/23 (39\%) of IVIg phases and 5/21 (24\%) of placebo phases and improvements of $\geq 2$ ONLS points in 3 patients, all during the IVIg phase. This finding suggested that a subset of patients responded to IVIg therapy. However, the effect may have been diluted by other patients who either (1) did not have a treatment-responsive neuropathy (i.e., diabetic polyneuropathy) or (2) had irreversible axonal loss, possibly related to a longer duration of neuropathy. Second, we noted a lack of significant effect in the subgroup of $18 / 25$ patients who met the EFNS electrophysiologic criteria for CIDP, ${ }^{38}$ possibly suggesting that these criteria are suboptimal in the setting of diabetes. In a previous publication from our group, we reported that in patients with CIDP with diabetes, increasing numbers of demyelinating features could not predict treatment responsiveness unlike in patients with CIDP but without DM. ${ }^{40}$ Despite the rarity of CIDP, modified diagnostic criteria in the setting of diabetes might be required. This concept has already been explored by the Lotan et al. ${ }^{41}$ group, who proposed a novel scoring system incorporating specific clinical features (namely-progressive/relapsing motor weakness of 2-6 months of duration, proximal involvement, upper limb weakness, large > small-fiber sensory impairment, and recent onset/ relatively well-controlled diabetes), electrophysiological features, and ancillary studies. Similarly, the Laughlin et al. ${ }^{25}$ publication used specific clinical criteria (symmetrical polyradiculoneuropathy lasting $>8$ weeks, with proximal and distal involvement, reduced reflexes, and large $>$ small-fiber sensory impairment) to preselect patients with suspected CIDP.

Our study results would seem to conflict with previous retrospective studies showing treatment responsiveness in patients with CIDP with diabetes. ${ }^{19,42}$ However, we believe that these retrospective studies may have had selection bias, whereby those patients reported to have CIDP and diabetic polyneuropathy were those who exhibited treatment response (hence confirming the clinical suspicion). Conversely, our current study answers the more practical clinical question of how to manage patients with diabetes presenting with demyelinating polyneuropathy features. In addition, the current study was specifically looking for improvement in the ONLS and R-ODS scores (validated outcome measures in CIDP), whereas other retrospective studies defined improvement based on MRC muscle scoring, Rankin scale, and global clinical impression — which are less specific to inflammatory neuropathies.
There are some limitations to our study that require mention. First, the allocation was performed in 5-subject blocks, which resulted in slight inequality in the initial phase (14 IVIg and 11 placebo). Second, there was an unblinded study coordinator in our clinic who was responsible for allocation design and for retrieving the product to be administered (which originated from the blood bank for IVIg and from the pharmacy for placebo). To mitigate this potential risk of breaking the blind, the coordinator was forbidden from speaking with other study personnel during the trial. However, we did not perform any post hoc surveys to determine whether this resulted in any unblinding. Third, the trial design may have influenced the outcome, as there were a small number of patients and short treatment phases in a chronic disorder, and it may be that longer treatment phases would have shown different results. Also, the interval of every 4 weeks for maintenance therapy may have undertreated patients, as some other trials have used q3week dosing. ${ }^{7}$ Fourth, there was a relatively high level of dropout (4/25 patients), although a sufficient number remained in the trial to perform adequately powered statistical calculations. Fifth, the primary end point looked for improvement in the ONLS score, but it may miss those patients who had subtle improvements or stopped deteriorating. Sixth, the duration of neuropathy at baseline may have been longer than expected in typical CIDP, favoring a diabetes-related etiology. Seventh, the clinical and electrodiagnostic inclusion criteria were relatively liberal and did not conform to published CIDP diagnostic criteria, thus risking the inclusion of routine diabetic polyneuropathy. However, this design was deliberate to simulate the clinical scenario of patients with diabetes and some suggestive/borderline CIDP features. Finally, there seems to have been a mild degree of carryover effect, which is a risk inherent in any crossover study.

In conclusion, this study provides Class I evidence that IVIg does not reduce disability in patients with demyelinating polyneuropathy features and diabetes. It is imperative that a careful history, clinical examination, and electrodiagnostic testing be used to recognize those patients with diabetes who have demyelinating abnormalities due to diabetes alone vs those who have true CIDP. This study does not exclude the possibility of CIDP in a patient with diabetes-but rather suggests that demyelinating changes on electrophysiology may be related to diabetes itself, thus not responsive to immunomodulatory treatment.

\section{Acknowledgment}

The authors acknowledge Ms. Mylan Ngo and Dr. Eduardo $\mathrm{Ng}$ for their assistance.

\section{Study funding}

This trial is funded by Grifols Therapeutics Inc.

\section{Dislosure}

A. Breiner reports pilot research grants from the GBS-CIDP Foundation and Grifols (the current study) and speaker or other honoraria from CSL Behring, Pfizer, Allergan, and 
Akcea Therapeutics. C. Barnett Tapia reports an investigatorinitiated research grant from Octapharma, consultant fees from UCB and CSL, and potential royalties from the MGII score. L.E. Lovblom reports no disclosures. B.A. Perkins reports grants from the CIHR, NIH, and JDRF, speaker honoraria from Medtronic, Johnson \& Johnson, Insulet, Abbott, Novo Nordisk, and Sanofi, and research grant support from Medtronic and Boehringer Ingelheim and serves as a consultant for Boehringer Ingelheim, Insulet, and Novo Nordisk. H.D. Katzberg reports clinical trial funding and investigator-initiated grants for CSL Behring, Octapharma, and Grifols and speaker fees, consulting, travel support, and/ or DSMB participation for CSL Behring, Amazentis, Flexpharma, Momenta, Octapharma, Terumo, Grifols, and Genzyme. V. Bril reports acting as a consultant for CSL Behring, UCB, Argenx, Alnylam, Alexion, Grifols, Octapharma, Takeda (Shire), and Pfizer. She has received research support from CSL Behring, UCB, Argenx, Grifols and Octapharma. Go to Neurology.org/NN for full disclosures.

\section{Publication history}

Received by Neurology: Neuroimmunology \& Neuroinflammation February 13, 2019. Accepted in final form May 28, 2019.

Appendix Authors

\begin{tabular}{|c|c|c|c|}
\hline Name & Location & Role & Contribution \\
\hline $\begin{array}{l}\text { Ari Breiner, } \\
\text { MD, MSc, } \\
\text { FRCPC }\end{array}$ & $\begin{array}{l}\text { University of } \\
\text { Ottawa, } \\
\text { Ottawa, } \\
\text { Canada }\end{array}$ & Author & $\begin{array}{l}\text { Conceived the study, wrote } \\
\text { the protocol, recruited } \\
\text { participants, collected data, } \\
\text { and wrote the first draft of } \\
\text { the manuscript }\end{array}$ \\
\hline
\end{tabular}

\begin{tabular}{|c|c|c|c|}
\hline $\begin{array}{l}\text { Carolina } \\
\text { Barnett, MD, } \\
\text { PhD }\end{array}$ & $\begin{array}{l}\text { University of } \\
\text { Toronto, } \\
\text { Toronto, } \\
\text { Canada }\end{array}$ & Author & $\begin{array}{l}\text { Advised on the protocol, } \\
\text { recruited participants, and } \\
\text { made substantial } \\
\text { contributions to the } \\
\text { drafting/revision of the } \\
\text { manuscript for intellectual } \\
\text { content }\end{array}$ \\
\hline
\end{tabular}

\begin{tabular}{|c|c|c|c|}
\hline $\begin{array}{l}\text { Leif Erik } \\
\text { Lovblom, } \\
\text { MSc }\end{array}$ & $\begin{array}{l}\text { University of } \\
\text { Toronto, } \\
\text { Toronto, } \\
\text { Canada }\end{array}$ & Author & $\begin{array}{l}\text { Performed data analysis } \\
\text { and drafted/revised } \\
\text { portions of the manuscript } \\
\text { related to data analysis. }\end{array}$ \\
\hline $\begin{array}{l}\text { Bruce A. } \\
\text { Perkins, MD, } \\
\text { MPH, FRCPC }\end{array}$ & $\begin{array}{l}\text { University of } \\
\text { Toronto, } \\
\text { Toronto, } \\
\text { Canada }\end{array}$ & Author & $\begin{array}{l}\text { Advised on the protocol, } \\
\text { recruited participants, and } \\
\text { made substantial } \\
\text { contributions to the } \\
\text { drafting/revision of the } \\
\text { manuscript for intellectual } \\
\text { content }\end{array}$ \\
\hline
\end{tabular}

\begin{tabular}{|c|c|c|c|}
\hline $\begin{array}{l}\text { Hans D. } \\
\text { Katzberg, } \\
\text { MD, MSc, } \\
\text { FRCPC }\end{array}$ & $\begin{array}{l}\text { University of } \\
\text { Toronto, } \\
\text { Toronto, } \\
\text { Canada }\end{array}$ & Author & $\begin{array}{l}\text { Advised on the protocol, } \\
\text { recruited participants, and } \\
\text { made substantial } \\
\text { contributions to the } \\
\text { drafting/revision of the } \\
\text { manuscript for intellectual } \\
\text { content }\end{array}$ \\
\hline
\end{tabular}

\begin{tabular}{lll}
\hline Vera Bril, & University of & Author \\
MD, FRCPC & $\begin{array}{l}\text { Conceived the study, wrote } \\
\text { Toronto, } \\
\text { Toronto, } \\
\text { Canada }\end{array}$ & $\begin{array}{l}\text { the protocol, recruited } \\
\text { participants, collected data, } \\
\text { and wrote the first draft of } \\
\text { the manuscript }\end{array}$ \\
& &
\end{tabular}

\section{References}

1. Köller H, Kieseier BC, Jander S, Hartung HP. Chronic inflammatory demyelinating polyneuropathy. N Engl J Med 2005;352:1343-1356.

2. Brannagan TH III. Current diagnosis of CIDP: the need for biomarkers. J Peripher nervous Syst 2011;16(suppl 1):3-13.

3. Van den Bergh PY, Rajabally YA. Chronic inflammatory demyelinating polyradiculoneuropathy. Presse Med 2013;42:e203-e215.

4. Dyck PJ, Litchy WJ, Kratz KM, et al. A plasma exchange versus immune globulin infusion trial in chronic inflammatory demyelinating polyradiculoneuropathy. Ann Neurol 1994;36:838-845.

5. Hahn AF, Bolton CF, Zochodne D, Feasby TE. Intravenous immunoglobulin treatment in chronic inflammatory demyelinating polyneuropathy. A double-blind, placebo-controlled, cross-over study. Brain 1996;119(pt 4):1067-1077.

6. Hughes $\mathrm{R}$, Bensa $\mathrm{S}$, Willison $\mathrm{H}$, et al. Randomized controlled trial of intravenous immunoglobulin versus oral prednisolone in chronic inflammatory demyelinating polyradiculoneuropathy. Ann Neurol 2001;50:195-201.

7. Hughes RA, Donofrio P, Bril V, et al. Intravenous immune globulin (10\% caprylatechromatography purified) for the treatment of chronic inflammatory demyelinating polyradiculoneuropathy (ICE study): a randomised placebo-controlled trial. Lancet Neurol 2008;7:136-144.

8. Mendell JR, Barohn RJ, Freimer ML, et al. Randomized controlled trial of IVIg in untreated chronic inflammatory demyelinating polyradiculoneuropathy. Neurology 2001;56:445-449.

9. Nobile-Orazio E, Cocito D, Jann S, et al. Intravenous immunoglobulin versus intravenous methylprednisolone for chronic inflammatory demyelinating polyradiculoneuropathy: a randomised controlled trial. Lancet Neurol 2012;11:493-502.

10. van Schaik IN, Eftimov F, van Doorn PA, et al. Pulsed high-dose dexamethasone versus standard prednisolone treatment for chronic inflammatory demyelinating polyradiculoneuropathy (PREDICT study): a double-blind, randomised, controlled trial. Lancet Neurol 2010;9:245-253.

11. Thompson N, Choudhary P, Hughes RA, Quinlivan RM. A novel trial design to study the effect of intravenous immunoglobulin in chronic inflammatory demyelinating polyradiculoneuropathy. J Neurol 1996;243:280-285.

12. De Sousa EA, Chin RL, Sander HW, Latov N, Brannagan TH III. Demyelinating findings in typical and atypical chronic inflammatory demyelinating polyneuropathy: sensitivity and specificity. J Clin Neuromuscul Dis 2009;10:163-169.

13. Dunnigan SK, Ebadi H, Breiner A, et al. Conduction slowing in diabetic sensorimotor polyneuropathy. Diabetes Care 2013;36:3684-3690.

14. Herrmann DN, Ferguson ML, Logigian EL. Conduction slowing in diabetic distal polyneuropathy. Muscle Nerve 2002;26:232-237.

15. Wilson JR, Stittsworth JD Jr, Kadir A, Fisher MA. Conduction velocity versus amplitude analysis: evidence for demyelination in diabetic neuropathy. Muscle Nerve 1998;21:1228-1230.

16. Behse F, Buchthal F, Carlsen F. Nerve biopsy and conduction studies in diabetic neuropathy. J Neurol Neurosurg Psychiatry 1977;40:1072-1082.

17. Younger DS, Rosoklija G, Hays AP. Peripheral nerve immunohistochemistry in diabetic neuropathy. Semin Neurol 1996;16:139-142.

18. Chio A, Plano F, Calvo A, et al. Comorbidity between CIDP and diabetes mellitus: only a matter of chance? Eur J Neurol 2009;16:752-754.

19. Gorson KC, Ropper AH, Adelman LS, Weinberg DH. Influence of diabetes mellitus on chronic inflammatory demyelinating polyneuropathy. Muscle Nerve 2000;23: 37-43.

20. Kalita J, Misra UK, Yadav RK. A comparative study of chronic inflammatory demyelinating polyradiculoneuropathy with and without diabetes mellitus. Eur J Neurol 2007; 14:638-643.

21. Sharma KR, Cross J, Farronay O, Ayyar DR, Shebert RT, Bradley WG. Demyelinating neuropathy in diabetes mellitus. Arch Neurol 2002;59:758-765.

22. Uncini A, De Angelis MV, Di Muzio A, et al. Chronic inflammatory demyelinating polyneuropathy in diabetics: motor conductions are important in the differential diagnosis with diabetic polyneuropathy. Clin Neurophysiol 1999;110:705-711.

23. Bril V, Blanchette CM, Noone JM, Runken MC, Gelinas D, Russell JW. The dilemma of diabetes in chronic inflammatory demyelinating polyneuropathy. J Diabetes Complications 2016;30:1401-1407.

24. Chiò A, Cocito D, Bottacchi E, et al. Idiopathic chronic inflammatory demyelinating polyneuropathy: an epidemiological study in Italy. J Neurol Neurosurg Psychiatry 2007;78:1349-1353.

25. Laughlin RS, Dyck PJ, Melton LJ III, Leibson C, Ransom J, Dyck PJ. Incidence and prevalence of CIDP and the association of diabetes mellitus. Neurology 2009;73:39-45.

26. Lozeron P, Nahum L, Lacroix C, Ropert A, Guglielmi JM, Said G. Symptomatic diabetic and non-diabetic neuropathies in a series of 100 diabetic patients. J Neurol 2002;249:569-575.

27. Latov N. Biomarkers of CIDP in patients with diabetes or CMT1.J Peripher Nerv Syst 2011;16(suppl 1):14-17.

28. Dunnigan SK, Ebadi H, Breiner A, et al. The characteristics of chronic inflammatory demyelinating polyneuropathy in patients with and without diabetes-an observational study. PLoS One 2014;9:e89344.

29. Dunnigan SK, Ebadi H, Breiner A, et al. Comparison of diabetes patients with "demyelinating" diabetic sensorimotor polyneuropathy to those diagnosed with CIDP. Brain Behav 2013;3:656-663.

30. American Diabetes Association. Diagnosis and classification of diabetes mellitus. Diabetes care 2010;33(suppl 1):S62-S69.

31. Graham RC, Hughes RA. A modified peripheral neuropathy scale: the Overall Neuropathy Limitations Scale. J Neurol Neurosurg Psychiatry 2006;77:973-976. 
32. van Nes SI, Vanhoutte EK, van Doorn PA, et al. Rasch-built Overall Disability Scale (RODS) for immune-mediated peripheral neuropathies. Neurology 2011;76:337-345.

33. AANEM. Recommended Policy for Electrodiagnostic Medicine. Am Acad Neuromuscul Electrodiagnostic Med 2004;1:1-16.

34. Bolton CF, Benstead TJ, Grand'Maison F, Tardif GS, Weston LE. Minimum standards for electromyography in Canada: a statement of the Canadian Society of Clinical Neurophysiologists. Can J Neurol Sci 2000;27:288-291.

35. Schoenfeld DA. Statistical considerations for clinical trials and scientific experiments [online]. Available at: hedwig.mgh.harvard.edu/sample size/size.html. Accessed January 29, 2015.

36. Merkies ISJ. Evaluation of Scales and Measurement Instruments in ImmuneMediated Polyneuropathy. Rotterdam: Erasmus University; 2001.

37. Merkies IS, van Nes SI, Hanna K, Hughes RA, Deng C. Confirming the efficacy of intravenous immunoglobulin in CIDP through minimum clinically important differences: shifting from statistical significance to clinical relevance. J Neurol Neurosurg Psychiatry 2010;81:1194-1199.

38. Van den Bergh PY, Hadden RD, Bouche P, et al. European Federation of Neurological Societies/Peripheral Nerve Society guideline on management of chronic inflammatory demyelinating polyradiculoneuropathy: report of a joint task force of the European Federation of Neurological Societies and the Peripheral Nerve Society-first revision. Eur J Neurol 2010;17:356-363.

39. Stewart JD, McKelvey R, Durcan L, Carpenter S, Karpati G. Chronic inflammatory demyelinating polyneuropathy (CIDP) in diabetics. J Neurol Sci 1996;142:59-64.

40. Abraham A, Breiner A, Katzberg HD, Lovblom LE, Perkins BA, Bril V. Treatment responsiveness in CIDP patients with diabetes is associated with unique electrophysiological characteristics, and not with common criteria for CIDP. Expert Rev Clin Immunol 2015;11:537-546.

41. Lotan I, Hellman MA, Steiner I. Diagnostic criteria of chronic inflammatory demyelinating polyneuropathy in diabetes mellitus. Acta Neurol Scand 2015;132: 278-283.

42. Haq RU, Pendlebury WW, Fries TJ, Tandan R. Chronic inflammatory demyelinating polyradiculoneuropathy in diabetic patients. Muscle Nerve 2003;27: 465-470. 


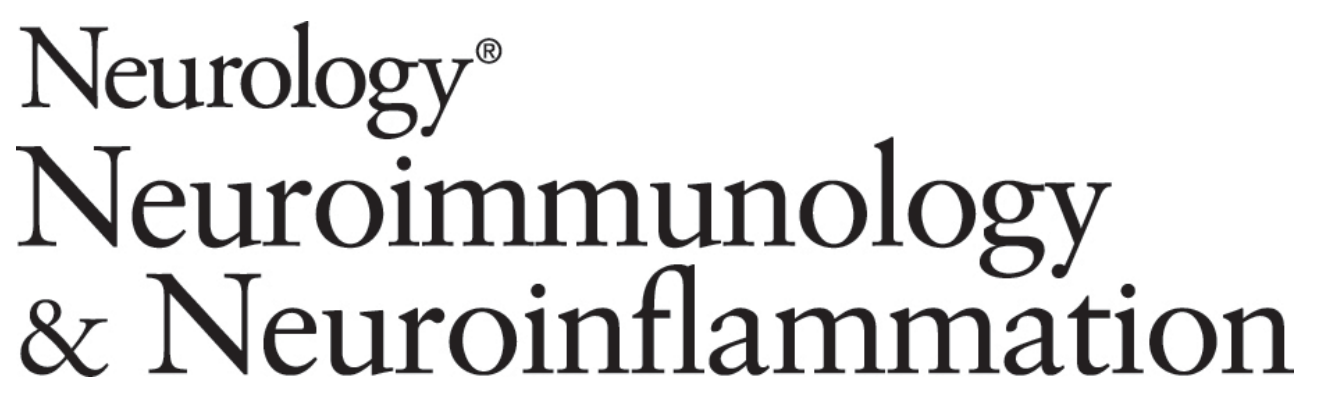

Randomized, controlled crossover study of IVIg for demyelinating polyneuropathy and diabetes

Ari Breiner, Carolina Barnett Tapia, Leif Erik Lovblom, et al.

Neurol Neuroimmunol Neuroinflamm 2019;6;

DOI 10.1212/NXI.0000000000000586

This information is current as of July 10, 2019

Neurol Neuroimmunol Neuroinflamm is an official journal of the American Academy of Neurology.

Published since April 2014, it is an open-access, online-only, continuous publication journal. Copyright

Copyright $\odot 2019$ The Author(s). Published by Wolters Kluwer Health, Inc. on behalf of the American

Academy of Neurology.. All rights reserved. Online ISSN: 2332-7812.

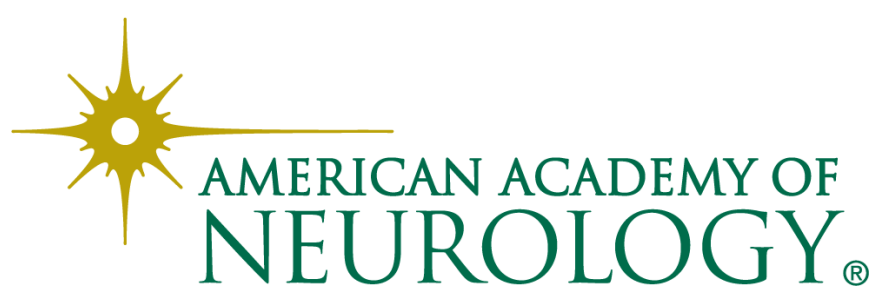




\section{Updated Information \& Services}

\section{References}

\section{Subspecialty Collections}

\section{Permissions \& Licensing}

\section{Reprints}

including high resolution figures, can be found at: http://nn.neurology.org/content/6/5/e586.full.html

This article cites 40 articles, 6 of which you can access for free at: http://nn.neurology.org/content/6/5/e586.full.html\#\#ref-list-1

This article, along with others on similar topics, appears in the following collection(s):

Chronic inflammatory demyelinating polyneuropathy

http://nn.neurology.org//cgi/collection/chronic_inflammatory_demyeli nating_polyneuropathy

Class I

http://nn.neurology.org//cgi/collection/class_1

Clinical trials Randomized controlled (CŌNSORT agreement)

http://nn.neurology.org//cgi/collection/clinical_trials_randomized_cont rolled_consort_agreement

\section{Peripheral neuropathy}

http://nn.neurology.org//cgi/collection/peripheral_neuropathy

Information about reproducing this article in parts (figures,tables) or in its entirety can be found online at:

http://nn.neurology.org/misc/about.xhtml\#permissions

Information about ordering reprints can be found online: http://nn.neurology.org/misc/addir.xhtml\#reprintsus

Neurol Neuroimmunol Neuroinflamm is an official journal of the American Academy of Neurology.

Published since April 2014, it is an open-access, online-only, continuous publication journal. Copyright

Copyright $\odot 2019$ The Author(s). Published by Wolters Kluwer Health, Inc. on behalf of the American Academy of Neurology.. All rights reserved. Online ISSN: 2332-7812.

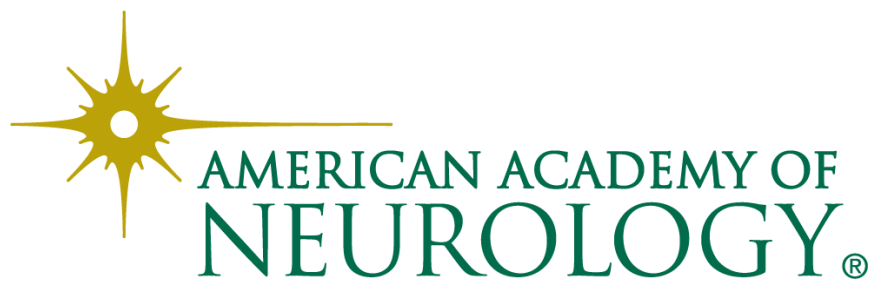

